\title{
Microvascular reactivity is altered early in patients with acute respiratory distress syndrome
}

Diego Orbegozo Cortés ${ }^{\dagger}$, Lokmane Rahmania $^{\dagger}$, Marian Irazabal, Carlos Santacruz, Vito Fontana, Daniel De Backer, Jacques Creteur and Jean-Louis Vincent ${ }^{*}$

\begin{abstract}
Background: Acute respiratory distress syndrome (ARDS) is associated with vascular endothelial dysfunction. The resultant microvascular reactivity can be assessed non-invasively using near-infrared spectroscopy (NIRS) and a vascular occlusion test (VOT) and changes have been correlated with severity of organ dysfunction and mortality in other critically ill populations. We used NIRS to study the presence of microcirculatory alterations in patients with ARDS.
\end{abstract}

Methods: We studied 27 healthy volunteers and 32 ARDS patients admitted to our intensive care department. NIRS measurements were performed within $24 \mathrm{~h}$ after diagnosis (Berlin definition). VOTs were performed by inflating an armcuff to a pressure greater than the systolic pressure for $3 \mathrm{~min}$, followed by rapid deflation. The descending (Desc) and ascending (Asc) thenar muscle oxygen saturation $\left(\mathrm{StO}_{2}\right)$ slopes were calculated. We compared data from volunteers with those from ARDS patients, from ARDS survivors and non-survivors, and from ARDS survivors who required $<7$ days ventilatory support (good evolution) with those who required $>7$ days support or died (poor evolution).

Results: ARDS patients had lower $\mathrm{StO}_{2}$ values [75(67-80) vs 79(76-81) \%, $\left.p=0.04\right]$ and Asc slopes [185(115-233) vs $258(216-306) \% / m i n, p<0.01]$ than healthy volunteers, but Desc slopes were similar. The Asc slope was lower in the patients with a poor evolution than in the other patients [121(90-209) vs 222(170-293) \%/min, $p<0.01$, and in the non-survivors than in the survivors [95(73-120) vs 212(165-252) \%/min, $p<0.01]$.

Conclusions: In ARDS patients, microvascular reactivity is altered early, and the changes are directly related to the severity of the disease. The ascending slope is the best determinant of outcome.

Keywords: Reactive hyperemia, Hypoxemia, Microcirculation, Prognosis, Mechanical ventilation

\section{Background}

Acute respiratory distress syndrome (ARDS), defined using the Berlin criteria [1], is diagnosed in 25 to $30 \%$ of patients admitted to the intensive care unit (ICU) who need mechanical ventilation for more than $24 \mathrm{~h}$ $[2,3]$, and is associated with high mortality rates [2-4] and long term sequelae $[5,6]$. The complex pathophysiological alterations include functional and morphological alterations in the pulmonary endothelium

\footnotetext{
*Correspondence: jlvincent@intensive.org

${ }^{\dagger}$ Equal contributors

Department of Intensive Care, Erasme University Hospital, Université Libre de Bruxelles, Route de Lennik 808, B-1070 Brussels, Belgium
}

[7], which may be correlated with the severity of the disease and outcomes [8-10].

Different options are available to study this endothelial dysfunction and the microcirculatory alterations that take place during ARDS. Invasive studies can be performed in animals to directly visualize the microcirculation using intra-vital video-microscopy [11]; levels of specific molecules (biomarkers) can be dosed in the plasma or in the bronchoalveolar fluid [12]; biopsies can be performed in selected cases [13]; or anatomopathological studies can be performed in the lungs of patients who die [7]. All these approaches have advantages and limitations. In clinical studies, the most invasive techniques can often not be applied and measurement 


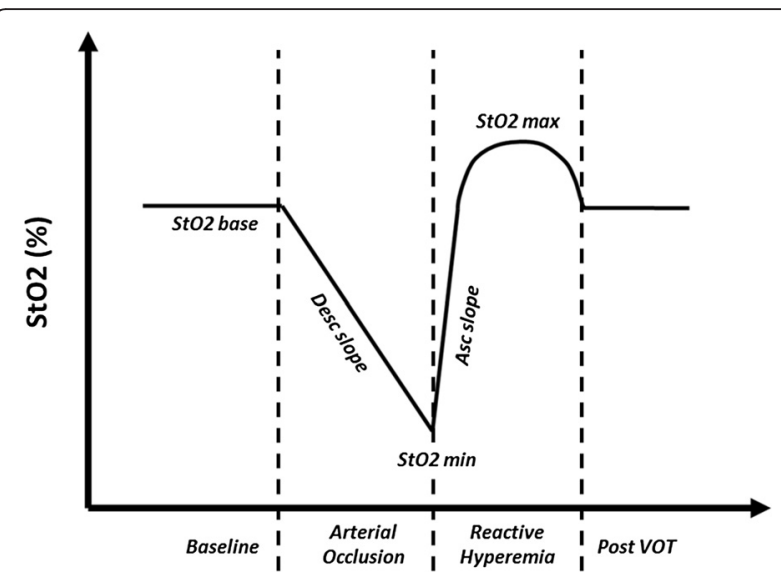

Fig. 1 Schematic representation of tissue oxygen saturation $\left(\mathrm{StO}_{2}\right)$ changes during a vascular occlusion test (VOT)

of concentrations of single biomarkers does not reflect the complex underlying pathophysiology [14, 15].

Assessment of complex microvascular responses can now be performed non-invasively at the patient's bedside using provocative tests of the microcirculation [16]. For example, using near-infrared spectroscopy (NIRS) it is possible to characterize the local muscle oxygen saturation $\left(\mathrm{StO}_{2}\right)$ by applying the properties of oxy- and deoxy-hemoglobin to infrared light [17]. If the arterial supply to a region is transiently obstructed by a vascular occlusion test (VOT), the rate of decrease in the $\mathrm{StO}_{2}$ (desaturation) is a reflection of local oxygen consumption [18], and the rate of increase (re-saturation) after the VOT is related to the post-occlusive microcirculatory vascular hyperemia [19]. This dynamic test has been used to demonstrate that microvascular reactivity is altered in patients with sepsis [20], multiple organ dysfunction [21], trauma [22], acute heart failure [23], cardiac surgery [24] or after cardiac arrest resuscitation [25] and that the changes are not entirely explained by global hemodynamic variables. However, there are no data currently available in patients with ARDS. We, therefore, used NIRS to evaluate the presence, severity and prognostic implications of early microcirculatory alterations in patients with ARDS.

\section{Methods}

This prospective, observational, non-invasive, physiological study was conducted in the 35-bed Department of Intensive Care of Erasme University Hospital (Brussels, Belgium). Institutional Ethical Committee approval was obtained, and all volunteers and patients (or their next of kin) provided written informed consent.

\section{Patients and volunteers}

Healthy adult volunteers were recruited from the hospital staff. Adult ICU patients with ARDS were enrolled between October 2013 and June 2015 when they fulfilled the Berlin diagnostic criteria [1], including a $\mathrm{PaO}_{2} / \mathrm{FiO}_{2}$ ratio $\leq 300$ on mechanical ventilation with a positive end-expiratory pressure (PEEP) of at least $5 \mathrm{cmH}_{2} \mathrm{O}$, and the presence of bilateral infiltrates on chest radiography, not explained by cardiogenic edema and in the presence of a risk factor for ARDS. Patients were stratified for severity using the $\mathrm{PaO}_{2} / \mathrm{FiO}_{2}$ ratio as recommended [1]. Patients were only included if a researcher was available to perform the NIRS measurements. All patients were managed according to current guidelines by a team of intensivists different from the researchers who performed the NIRS measurements.

\section{Protocol}

The healthy volunteers were placed in a quiet, temperature controlled room within the department of intensive care, where they rested, comfortably seated for at least $15 \mathrm{~min}$ before the experiment. Heart rate (HR), respiratory rate (RR) and hemoglobin saturation by pulse oximetry $\left(\mathrm{SpO}_{2}\right)$ were evaluated non-invasively with a Siemens SC 9000 monitor (Siemens, Erlangen, Germany). Noninvasive measurements of mean arterial pressure (MAP) were obtained on the opposite arm to that used for the NIRS measurements.

All patients were studied within $24 \mathrm{~h}$ after the diagnosis of ARDS was made. At the time when the NIRS VOT was performed, we recorded all measured hemodynamic and respiratory parameters from the monitoring systems. Biochemical and laboratory data closest to the time of the VOT were also recorded as was the presence or absence of any sedation. An APACHE II score [26] was calculated using the worst data during the first $24 \mathrm{~h}$ in the ICU, and a sequential organ failure assessment (SOFA) score [27] from the data present at the time of the NIRS measurements. We also recorded the duration of mechanical ventilation until definitive weaning from ventilatory support and calculated the ventilator-free days (VFD) at 28-days, giving a value of zero to non-survivors.

Survivors who required less than 7 days (arbitrarily selected) of respiratory support were classified as having a good evolution and those who required more than 7 days of mechanical ventilation or who died as having a poor evolution.

\section{NIRS measurements}

$\mathrm{StO}_{2}$ was measured using a near-infrared spectrometer (InSpectra 850 model, Hutchinson Technology, Hutchinson, Minnesota), with a $15 \mathrm{~mm}$-probe attached to a fixed position on the thenar eminence (on the opposite hand from the arm with the invasive arterial line monitoring if present). Healthy volunteers and conscious patients were asked not to move their hand during the procedure. When the $\mathrm{StO}_{2}$ values had 
Table 1 Main characteristics of the healthy volunteers and the ARDS patients at the time of the VOT

\begin{tabular}{|c|c|c|c|c|}
\hline \multirow[t]{2}{*}{ VARIABLE } & \multirow{2}{*}{$\begin{array}{l}\text { Volunteers } \\
(n=27)\end{array}$} & \multicolumn{3}{|l|}{ ARDS } \\
\hline & & Total $(n=32)$ & Good evolution $(n=16)$ & Poor evolution $(n=16)$ \\
\hline Age (years) & $30(27-31)^{*}$ & $63(48-71)$ & $68(46-78)$ & $61(51-66)$ \\
\hline Male n(\%) & $15(56)$ & $21(66)$ & $12(75)$ & $9(56)$ \\
\hline Body mass index $\left(\mathrm{Kg} / \mathrm{m}^{2}\right)$ & $23(22-25)^{*}$ & $26(23-29)$ & $25(24-28)$ & $27(22-30)$ \\
\hline Mean arterial pressure $(\mathrm{mmHg})$ & $88(83-91)$ & $82(75-89)$ & $83(80-93)$ & $78(72-87)$ \\
\hline Heart rate (bpm) & $74(70-79)^{*}$ & $95(81-104)$ & $96(81-105)$ & $95(83-102)$ \\
\hline Respiratory rate (bpm) & $12(12-13)^{*}$ & $24(19-30)$ & $23(18-30)$ & $24(20-31)$ \\
\hline $\mathrm{SpO}_{2}$ & $98(98-99)^{*}$ & 97 (95-99) & 97 (95-99) & 98 (96-99) \\
\hline Hemoglobin $\mathrm{O}_{2}$ saturation (\%) & - & 97 (95-99) & 97 (95-99) & $98(96-100)$ \\
\hline Temperature $\left({ }^{\circ} \mathrm{C}\right)$ & - & $37.0(36.3-37.5)$ & $37.1(36.6-37.6)$ & $36.7(36.1-37.2)$ \\
\hline Sepsis n(\%) & - & $16(50)$ & $7(44)$ & $9(56)$ \\
\hline Primary ARDS n(\%) & - & $9(28)$ & $5(31)$ & $4(25)$ \\
\hline Trauma n(\%) & - & $4(13)$ & $2(13)$ & $2(13)$ \\
\hline Surgery n(\%) & - & $18(56)$ & $12(75)$ & $6(38)$ \\
\hline Chronic lung disease $\mathrm{n}(\%)$ & - & $5(16)$ & $1(6)$ & $4(25)$ \\
\hline Inspired $\mathrm{O}_{2}$ fraction (\%) & - & $50(40-55)$ & $50(33-50)$ & $50(40-70)$ \\
\hline Positive end-expiratory pressure $\left(\mathrm{cmH}_{2} \mathrm{O}\right)$ & - & $6(5-8)$ & $7(6-8)$ & $5(5-11)$ \\
\hline $\mathrm{PaO}_{2} / \mathrm{FiO}_{2}$ ratio & - & $172(126-231)$ & $181(126-243)$ & $172(128-223)$ \\
\hline $\mathrm{pH}$ & - & $7.39(7.34-7.44)$ & $7.40(7.34-7.44)$ & $7.38(7.33-7.45)$ \\
\hline $\mathrm{PCO}_{2}(\mathrm{mmHg})$ & - & $37(36-44)$ & $37(36-43)$ & $38(35-53)$ \\
\hline Lactate $(\mathrm{mmol} / \mathrm{L})$ & - & $1.4(0.8-2.5)$ & $1.4(0.8-3.2)$ & $1.5(0.9-2.3)$ \\
\hline Creatinine $(\mathrm{mg} / \mathrm{dL})$ & - & $1.1(0.7-1.6)$ & $1.1(0.8-1.4)$ & $1.0(0.6-2.0)$ \\
\hline Renal replacement therapy n(\%) & - & $4(13)$ & $1(6)$ & $3(19)$ \\
\hline Total bilirubin (mg/dL) & - & $0.7(0.5-1.1)$ & $0.6(0.5-1.1)$ & $0.8(0.6-1.3)$ \\
\hline Platelets $\left(\times 10^{3} / \mu \mathrm{L}\right)$ & - & $129(91-197)$ & $143(84-226)$ & $121(95-192)$ \\
\hline Leukocytes (cells $\times 10^{3} / \mu \mathrm{L}$ ) & - & $13.0(9.4-16.7)$ & $13.9(11.9-16.2)$ & $11.7(7.6-17.9)$ \\
\hline Hemoglobin (mg/dL) & - & $9.6(8.9-11.2)$ & $9.6(9.0-10.8)$ & $9.7(8.6-11.5)$ \\
\hline Sedation n(\%) & - & $19(59)$ & $8(50)$ & $11(69)$ \\
\hline APACHE II score & - & $22(19-26)$ & $21(18-23)$ & $25(21-28)^{* *}$ \\
\hline SOFA score & - & $9(7-13)$ & $8(5-11)$ & $11(7-15)$ \\
\hline Norepinephrine (mcg/Kg/min) & - & $0.01(0.00-0.17)$ & $0.00(0.00-0.05)$ & $0.07(0.00-0.27)$ \\
\hline Dobutamine (mcg/Kg/min) & - & $0(0-3)$ & $0(0-2)$ & $0(0-5)$ \\
\hline ICU length of stay (days) & - & $7.7(4.4-13.7)$ & $6.0(4.0-7.7)$ & $11.9(7.3-20.6)^{* *}$ \\
\hline Ventilator free days at 28 days (days) & - & $21(0-25)$ & $25(24-26)$ & $0(0-17)^{* *}$ \\
\hline Mortality n(\%) & - & $8(25)$ & $0(0)$ & $8(50)^{* *}$ \\
\hline
\end{tabular}

*significant difference at the $p<0.05$ level versus ARDS patients; ${ }^{* *}$ significant difference at the $p<0.05$ level versus good evolution

been stable for $1 \mathrm{~min}$, we induced a VOT by rapidly inflating a sphygmomanometer cuff wrapped around the ipsilateral arm, to a pressure of $50 \mathrm{mmHg}$ above the systolic arterial pressure for a period of $3 \mathrm{~min}$ (time threshold), followed by a rapid deflation. The $\mathrm{StO}_{2}$ curves were then analyzed using dedicated software (In Spectra Software Analyzer version 3.0., Hutchinson Technology). We measured the baseline, minimal and maximal $\mathrm{StO}_{2}\left(\mathrm{StO}_{2}\right.$ base, $\mathrm{StO}_{2}$ min and $\mathrm{StO}_{2}$ max, respectively) and total hemoglobin index (THI base, THI min and THI max, respectively). We also computed the $\mathrm{StO}_{2}$ ascending (Asc) and descending (Desc) slopes (Fig. 1).

\section{Statistical analysis}

Statistical analysis was performed using SPSS 22.0 (IBM, New York, NY) software. Dependent variables were assessed for normality of distribution using Skewness and Kurtosis tests and Q-Q plots. All values are presented as 
Table 2 NIRS variables in healthy volunteers and ARDS patients

\begin{tabular}{|c|c|c|c|c|c|c|}
\hline \multirow[t]{2}{*}{ NIRS VARIABLE } & \multirow{2}{*}{$\begin{array}{l}\text { VOLUNTEERS } \\
(n=27)\end{array}$} & \multicolumn{5}{|l|}{ ARDS } \\
\hline & & Total $(n=32)$ & Good evolution $(n=16)$ & Poor evolution $(n=16)$ & Survivors $(n=24)$ & Non-survivors $(n=8)$ \\
\hline $\mathrm{StO}_{2}$ base (\%) & $79(76-81)$ & $75(67-80)^{*}$ & $77(72-80)$ & $74(60-80)$ & $77(73-80)$ & $60(59-76)^{*}$ \\
\hline THI base (au) & $14.4(12.8-15.4)$ & $9.6(6.8-10.8)^{* *}$ & $9.7(7.7-10.8)$ & $9.0(6.8-10.9)$ & $9.8(6.8-10.8)$ & $7.9(6.7-11.7)$ \\
\hline $\mathrm{StO}_{2} \max (\%)$ & $94(90-94)$ & $85(76-90)^{* *}$ & $87(82-90)$ & $84(73-90)$ & 87 (83-93) & $73(70-84)^{*}$ \\
\hline Desc slope $(\% / \mathrm{min})$ & $10.3(8.4-11.4)$ & $9.6(8.2-13.4)$ & $11.3(8.7-15.8)$ & $8.8(7.2-13.2)$ & $11.3(8.7-15.3)$ & $8.1(5.7-9.1)^{* *}$ \\
\hline Asc slope (\%/min) & $258(216-306)$ & $185(115-233)^{* *}$ & $222(170-293)$ & $121(90-209)^{* *}$ & $212(165-252)$ & $95(73-120)^{* *}$ \\
\hline
\end{tabular}

${ }^{*}=p<0.05$ and ${ }^{* *}=p<0.01$, ARDS patients compared to healthy volunteers, poor evolution compared to good evolution, and non-survivors compared to survivors

median values with percentiles (25-75\%), unless otherwise specified. Categorical data are presented as numbers of events and percentages. Comparisons between different cohorts were performed using a $t$-test, Mann-Whitney $U$ test or Kruskal-Wallis $\mathrm{H}$ test as appropriate. Proportions were compared with a Chi square test or Fisher's exact test as appropriate. A binary logistic regression was performed to identify the role of different variables to predict poor evolution, calculating the odds ratio (OR) and its respective $95 \%$ confidence interval $(\mathrm{CI})$. All variables that presented a $\mathrm{p}$ value $<0.1$ during the univariate analysis were introduced into a multivariate analysis. We plotted the sensitivities and specificities in receiving operating characteristic (ROC) graphs and the area under the curve (AUC) was calculated for the different variables. A 2-sided p value less than 0.05 was considered as significant for all analyses.

\section{Results}

Twenty-seven healthy volunteers were recruited (mean age 30 [range 27-31] years; 15 male) and 32 patients with ARDS (mean age 63 [range 48-71], 21 male). The main demographic, clinical and biochemical characteristics of the volunteers and patients are presented in
Table 1. The characteristics of ARDS survivors and nonsurvivors are shown in Additional file 1: Table S1.

NIRS derived parameters are shown in Table 2. ARDS patients had lower $\mathrm{StO}_{2}$ values and Asc slope, but not Desc slope, than healthy volunteers. Patients with a poor evolution had a lower NIRS Asc slope than those with a good evolution (Fig. 2a), but $\mathrm{StO}_{2}$ and Desc slope values were not significantly different (Table 2). Likewise, non-survivors had a lower NIRS Asc slope than survivors (Fig. 2b). There were no differences in the Asc slope values according to the cause of ARDS (including sepsis and its severity) (Additional file 1: Figure S1 and S2).

There were no significant differences in the $\mathrm{PaO}_{2} /$ $\mathrm{FiO}_{2}$ ratio between patients with a good or poor evolution, or between survivors and non-survivors (Tables 1 and Additional file 1: Table S1). However, ARDS patients with a $\mathrm{PaO}_{2} / \mathrm{FiO}_{2}$ ratio $<100$ had a lower NIRS Asc slope than those with a $\mathrm{PaO}_{2} / \mathrm{FiO}_{2}$ ratio between 201 and 300 (Fig. 3).

The NIRS Asc slope was a better predictor of poor evolution (and of mortality alone) than the $\mathrm{PaO}_{2} / \mathrm{FiO}_{2}$ ratio (Fig. 4). This was confirmed in the multivariate analysis in which the NIRS Asc slope was the most
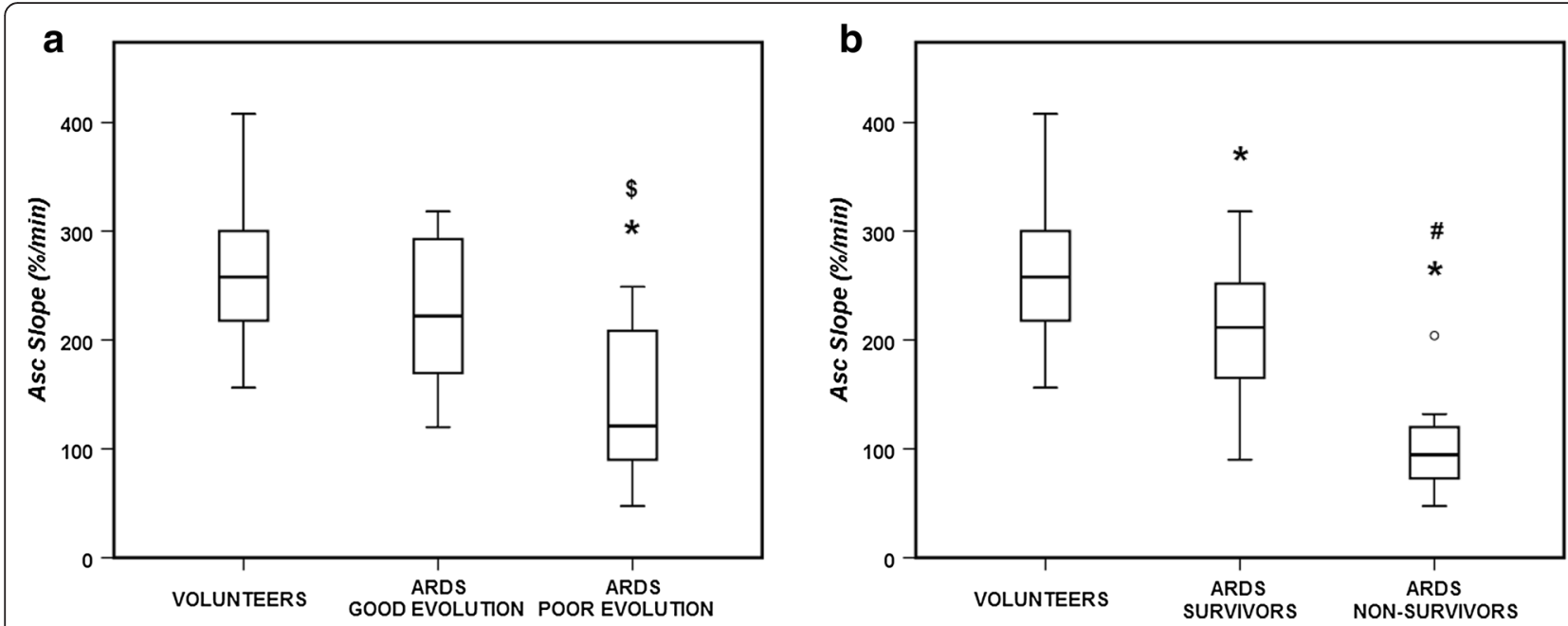

Fig. 2 NIRS Asc slope in healthy volunteers and patients with ARDS according to evolution (a) and survival status (b). * $=p<0.05$ compared with the volunteers; $\$=p<0.05$ compared with patients with good evolution; \# $=p<0.05$ compared with the survivors 


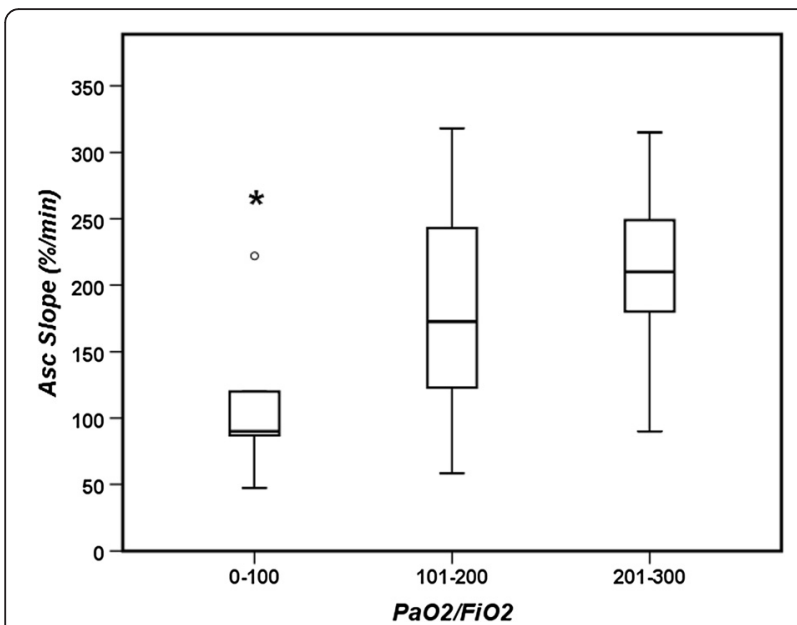

Fig. 3 NIRS Asc slope in ARDS patients according to their $\mathrm{PaO}_{2} / \mathrm{FiO}_{2}$ ratio. ${ }^{*}=p<0.05$ compared with the patients with a $\mathrm{PaO}_{2} / \mathrm{FiO}_{2}$ ratio between 201-300

significant factor associated with a poor evolution during the ICU stay (Additional file 1: Tables S2 and S3).

\section{Discussion}

The main finding of our study is that ARDS patients have altered peripheral microvascular reactivity as assessed using NIRS. This alteration is directly related to the severity of the disease characterized as death and/or prolonged need for mechanical ventilation.

The only published data on microcirculatory alterations in humans with acute respiratory failure assessed using non-invasive techniques were reported by our group in a small series of patients with acute lung injury due to Influenza AH1N1 [28]. These patients had diminished capillary density in the sublingual area, with a low proportion of perfused vessels and a reduced microvascular flow index. In the thenar muscle, postocclusive reactive hyperemia was impaired, as manifest by low values of the Asc slope, similar to those found in septic patients in other studies [29-31]. Our current study extends these data to a larger and more heterogeneous population of patients with ARDS.

Half of the patients in our study had sepsis, but microcirculatory alterations detected by NIRS are not pathognomonic of septic conditions. Numerous studies have shown alterations of the Asc slope in septic populations, especially in the presence of shock $[20,29,30]$, but low values of the Asc slope have also been observed in other acute conditions (normal values of 288 and $323 \% / \mathrm{min}$ have been reported [20, 22]): Gomez et al. reported values of $172 \pm 103 \% / \mathrm{min}$ in trauma patients [22]; Petroni et al. reported values of $77 \pm 42 \% / \mathrm{min}$ in patients with severe acute heart failure requiring venoarterial extracorporeal membrane oxygenation (ECMO) support [23]; Morel et al. reported values of 144 (126228) \%/min $6 \mathrm{~h}$ after cardiopulmonary bypass in patients who had undergone cardiac surgery [24]; Donadello et al. reported values of $68 \pm 32 \% / \mathrm{min}$ in resuscitated cardiac arrest patients after cessation of therapeutic hypothermia [25]; and we previously reported values of $186 \pm 89 \% / \mathrm{min}$ in patients with circulatory shock of different etiologies [31]. In the present study, patients with septic shock had similar Asc slope values to patients with ARDS of non-septic causes. Although the mechanisms involved in the control of post-occlusive reactive hyperemia (NIRS Asc slope) have not been completely identified and are sometimes controversial $[32,33]$, it is well known that multiple vasodilator pathways (e.g., nitric oxide and prostaglandins) are necessary to obtain the transient increase in local blood flow [32] and complex inflammatory alterations will have been present in
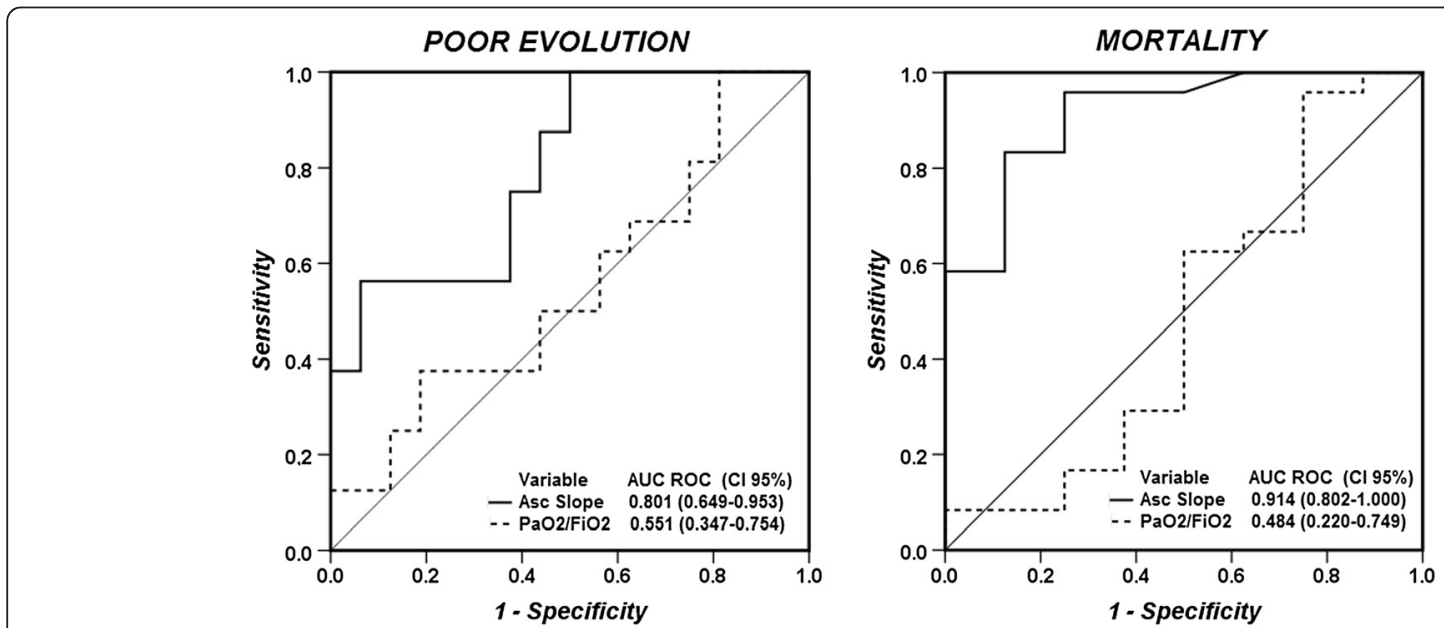

Fig. 4 Receiver operating characteristic (ROC) curves for Asc slope and $\mathrm{PaO}_{2} / \mathrm{FiO}_{2}$ ratio to predict death (right panel) or poor evolution (death or more than 7 days of mechanical ventilation; left panel) 
all the populations studied above [20, 22-25, 31]. Thus, the NIRS VOT is a functional test of the microcirculation, which measures its reserve (recruitability) under controlled ischemia, and involves multiple pathways.

Our findings suggest that microvascular endothelial dysfunction is present in the earliest stages of ARDS and is correlated with its severity. This concept fits well with the elevated concentrations of various pro-inflammatory molecules seen in patients with ARDS $[8,12,34]$ and with autopsy findings revealing an initial pro-inflammatory and exudative phase $[7,35]$. Dolinay and colleagues performed a series of experiments in mice and various cohorts of ARDS patients and showed that several inflammasomeregulated cytokines, including interleukin-18, play a major role in the development of ARDS [36]. Orfanos and colleagues demonstrated that severe ARDS was associated with decreased pulmonary capillary endothelium-bound angiotensin converting enzyme (ACE) function in vivo (an indirect marker of endothelial injury) [37]. More recently, Moussa et al. demonstrated that patients with ARDS in the context of sepsis had elevated numbers of circulating endothelial cells (a direct marker of endothelial injury), which were correlated with severity [10].

Early prognostication of outcome in ARDS is challenging. In large databases, the mortality rate is directly related to the severity of the alterations in gas exchange as expressed by the $\mathrm{PaO}_{2} / \mathrm{FiO}_{2}$ ratio, but the relationship is not very strong $[38,39]$, with an AUC of only 0.58 in a recent multicenter study [1]. We used a main combined outcome of death or need for prolonged mechanical ventilation which is essentially the opposite of ventilator-free days [40], but we also observed positive results when mortality was considered alone. Previous investigators have tried to predict similar combined outcomes, but they needed to use clinical data obtained during the first three days of hospitalization [41], rather than just on the first day as in the present study. Other groups have developed scores mixing various clinical and demographic data at admission, but these were not superior to the APACHE II score for predicting mortality [42]. We also observed that those patients who recovered rapidly had a similar Asc slope when compared with volunteers, despite the severe hypoxemia. Additionally, the NIRS Asc slope was the best predictor for death or more than 7 days on mechanical ventilation. Together these observations suggest that performing a NIRS VOT test on the first day of ARDS enables identification of patients at high-risk of poor outcome, potentially creating a target population for the testing of early interventions.

Our study has some limitations. First, it was a monocenter study and patient enrolment depended on researcher availability, although we included a heterogeneous sample of patients with different severities of ARDS. Second, we performed a single measurement and the time course of the Asc slope during subsequent days of treatment may provide additional information, as has been shown in septic patients [20]. Third, our control group was comprised of healthy younger individuals who may have different vascular reactivity to that of ARDS patients. However, we have previously reported that NIRS values are quite similar in control cohorts of patients and in healthy younger volunteers [20,31]. Our comparison enables the whole spectrum from the normal values of health to those in severe ARDS patients to be considered. Finally, the sample size of our population was small, potentially explaining the non-significant differences in some variables, for example, the norepinephrine doses between patients with good and poor evolution (Table 1) or the NIRS Asc slope in the different groups of $\mathrm{PaO}_{2} / \mathrm{FiO}_{2}$ ratios, despite trends in the data. Nevertheless, the clinical relevance of the NIRS Asc slope was higher than that of other studied variables and this variable needs to be investigated further.

\section{Conclusion}

In ARDS patients, there is an early, marked alteration in microvascular reactivity, which is directly related to the severity of the disease as reflected by the duration of mechanical ventilation and mortality.

\section{Additional file}

Additional file 1: Table S1. Main characteristics of ARDS survivors and non-survivors. Table S2. Univariate analysis of variables to predict death or more than 7 days of mechanical ventilation. Table S3. Multivariable analysis of variables to predict death or more than 7 days of mechanical ventilation. Figure S1. Comparison of NIRS Asc slope in different groups of ARDS patients. Figure S2. Comparison of NIRS Asc slope in different groups of ARDS patients according to the presence or not of sepsis and septic shock. (DOCX 79 kb)

\section{Competing interest}

The authors declare that they have no competing interest.

Authors' contributions

DOC, LR, DDB, JC, JLV conceived and designed the study; DOC, LR and CS performed and analyzed all NIRS measurements; DOC, LR, MI and VF screened and collected data from the population; DOC and LR wrote the first draft of the manuscript. DOC, LR, MI, CS, VF, DDB, JC and JLV revised the text for intellectual content. All the co-authors read and approved the final text.

Funding

Institutional funds only.

Received: 30 December 2015 Accepted: 5 May 2016

Published online: 17 May 2016

References

1. Ranieri VM, Rubenfeld GD, Thompson BT, Ferguson ND, Caldwell E, Fan E, et al. Acute respiratory distress syndrome: the Berlin definition. JAMA. 2012;307:2526-33

2. Rubenfeld GD, Caldwell E, Peabody E, Weaver J, Martin DP, Neff M, et al. Incidence and outcomes of acute lung injury. N Engl J Med. 2005;353:1685-93.

3. Azevedo LC, Park M, Salluh Jl, Rea-Neto A, Souza-Dantas VC, Varaschin $P$, et al. Clinical outcomes of patients requiring ventilatory support in Brazilian intensive care units: a multicenter, prospective, cohort study. Crit Care. 2013;17:R63. 
4. Mikkelsen ME, Shah CV, Meyer NJ, Gaieski DF, Lyon S, Miltiades AN, et al. The epidemiology of acute respiratory distress syndrome in patients presenting to the emergency department with severe sepsis. Shock. 2013; 40:375-81.

5. Bienvenu OJ, Colantuoni E, Mendez-Tellez PA, Dinglas VD, Shanholtz C, Husain N, et al. Depressive symptoms and impaired physical function after acute lung injury: a 2-year longitudinal study. Am J Respir Crit Care Med. 2012;185:517-24.

6. Linko R, Suojaranta-Ylinen R, Karlsson S, Ruokonen E, Varpula T, Pettila V. One-year mortality, quality of life and predicted life-time cost-utility in critically ill patients with acute respiratory failure. Crit Care. 2010;14:R60.

7. Thille AW, Esteban A, Fernandez-Segoviano P, Rodriguez JM, Aramburu JA, Vargas-Errazuriz P, et al. Chronology of histological lesions in acute respiratory distress syndrome with diffuse alveolar damage: a prospective cohort study of clinical autopsies. Lancet Respir Med. 2013;1:395-401.

8. Cross LJ, Matthay MA. Biomarkers in acute lung injury: insights into the pathogenesis of acute lung injury. Crit Care Clin. 2011;27:355-77.

9. Orfanos SE, Mavrommati I, Korovesi I, Roussos C. Pulmonary endothelium in acute lung injury: from basic science to the critically ill. Intensive Care Med. 2004;30:1702-14

10. Moussa MD, Santonocito C, Fagnoul D, Donadello K, Pradier O, Gaussem P, et al. Evaluation of endothelial damage in sepsis-related ARDS using circulating endothelial cells. Intensive Care Med. 2015;41:231-8.

11. Ivanov KP, Potekhina IL, Alyukhin YS, Melnikova NN. Microcirculation in the lungs: special features of construction and dynamics. Adv Exp Med Biol. 2013;756:197-201.

12. Schutte H, Lohmeyer J, Rosseau S, Ziegler S, Siebert $\mathrm{C}$, Kielisch $\mathrm{H}$, et al. Bronchoalveolar and systemic cytokine profiles in patients with ARDS, severe pneumonia and cardiogenic pulmonary oedema. Eur Respir J. 1996;9:1858-67.

13. Patel SR, Karmpaliotis D, Ayas NT, Mark EJ, Wain J, Thompson BT, et al. The role of open-lung biopsy in ARDS. Chest. 2004;125:197-202.

14. Ware LB, Koyama T, Billheimer DD, Wu W, Bernard GR, Thompson BT, et al. Prognostic and pathogenetic value of combining clinical and biochemical indices in patients with acute lung injury. Chest. 2010;137:288-96.

15. Bhargava M, Becker TL, Viken KJ, Jagtap PD, Dey S, Steinbach MS, et al. Proteomic profiles in acute respiratory distress syndrome differentiates survivors from non-survivors. PLoS One. 2014;9, e109713.

16. De Backer D, Donadello K, Cortes DO. Monitoring the microcirculation. J Clin Monit Comput. 2012;26:361-6.

17. Mancini DM, Bolinger L, Li H, Kendrick K, Chance B, Wilson JR. Validation of near-infrared spectroscopy in humans. J Appl Physiol (1985). 1994;77:2740-7.

18. Van Beekvelt MC, Colier WN, Wevers RA, Van Engelen BG. Performance of near-infrared spectroscopy in measuring local $\mathrm{O}(2)$ consumption and blood flow in skeletal muscle. J Appl Physiol (1985). 2001;90:511-9.

19. Bopp CM, Townsend DK, Barstow TJ. Characterizing near-infrared spectroscopy responses to forearm post-occlusive reactive hyperemia in healthy subjects. Eur J Appl Physiol. 2011;111:2753-61.

20. Creteur J, Carollo T, Soldati G, Buchele G, De Backer D, Vincent JL. The prognostic value of muscle $\mathrm{StO} 2$ in septic patients. Intensive Care Med. 2007;33:1549-56.

21. Doerschug KC, Delsing AS, Schmidt GA, Haynes WG. Impairments in microvascular reactivity are related to organ failure in human sepsis. Am J Physiol Heart Circ Physiol. 2007;293:H1065-71.

22. Gomez H, Torres A, Polanco P, Kim HK, Zenker S, Puyana JC, et al. Use of non-invasive NIRS during a vascular occlusion test to assess dynamic tissue O(2) saturation response. Intensive Care Med. 2008;34:1600-7.

23. Petroni T, Harrois A, Amour J, Lebreton G, Brechot N, Tanaka S, et al. Intraaortic balloon pump effects on macrocirculation and microcirculation in cardiogenic shock patients supported by venoarterial extracorporeal membrane oxygenation. Crit Care Med. 2014;42:2075-82.

24. Morel J, Bouchet JB, Vola M, Beraud AM, Clerc M, Awad S, et al. Tissue near infra red spectroscopy change is not correlated with patients' outcome in elective cardiac surgery. Acta Anaesthesiol Scand. 2014;58:835-42.

25. Donadello K, Favory R, Salgado-Ribeiro D, Vincent JL, Gottin L, Scolletta S, et al. Sublingual and muscular microcirculatory alterations after cardiac arrest: a pilot study. Resuscitation. 2011;82:690-5.

26. Knaus WA, Draper EA, Wagner DP, Zimmerman JE. APACHE II: a severity of disease classification system. Crit Care Med. 1985;13:818-29.

27. Vincent JL, Moreno R, Takala J, Willatts S, De Mendonca A, Bruining H, et al. The SOFA (Sepsis-related Organ Failure Assessment) score to describe organ dysfunction/failure. On behalf of the Working Group on Sepsis-Related
Problems of the European Society of Intensive Care Medicine. Intensive Care Med. 1996:22:707-10.

28. Salgado DR, Ortiz JA, Favory R, Creteur J, Vincent JL, De Backer D. Microcirculatory abnormalities in patients with severe influenza A (H1N1) infection. Can J Anaesth. 2010;57:940-6.

29. Payen D, Luengo C, Heyer L, Resche-Rigon M, Kerever S, Damoisel C, et al. Is thenar tissue hemoglobin oxygen saturation in septic shock related to macrohemodynamic variables and outcome? Crit Care. 2009;13 Suppl 5:S6.

30. Shapiro NI, Arnold R, Sherwin R, O'Connor J, Najarro G, Singh S, et al. The association of near-infrared spectroscopy-derived tissue oxygenation measurements with sepsis syndromes, organ dysfunction and mortality in emergency department patients with sepsis. Crit Care. 2011;15:R223.

31. Orbegozo Cortes D, Puflea F, De Backer D, Creteur J, Vincent JL. Near infrared spectroscopy (NIRS) to assess the effects of local ischemic preconditioning in the muscle of healthy volunteers and critically ill patients. Microvasc Res. 2015;102:25-32.

32. Engelke KA, Halliwill JR, Proctor DN, Dietz NM, Joyner MJ. Contribution of nitric oxide and prostaglandins to reactive hyperemia in human forearm. J Appl Physiol (1985). 1996;81:1807-14.

33. Skibsted S, Arnold R, Sherwin R, Singh S, Lundy D, Nelson T, et al. The association of near infrared spectroscopy-derived $\mathrm{StO} 2$ measurements and biomarkers of endothelial activation in sepsis. Intern Emerg Med. 2013:8:529-36.

34. Boxer LA, Axtell $R$, Suchard $S$. The role of the neutrophil in inflammatory diseases of the lung. Blood Cells. 1990:16:25-40.

35. Bull TM, Clark B, McFann K, Moss M. Pulmonary vascular dysfunction is associated with poor outcomes in patients with acute lung injury. Am J Respir Crit Care Med. 2010;182:1123-8.

36. Dolinay T, Kim YS, Howrylak J, Hunninghake GM, An CH, Fredenburgh L, et al. Inflammasome-regulated cytokines are critical mediators of acute lung injury. Am J Respir Crit Care Med. 2012;185:1225-34.

37. Orfanos SE, Armaganidis A, Glynos C, Psevdi E, Kaltsas P, Sarafidou P, et al. Pulmonary capillary endothelium-bound angiotensin-converting enzyme activity in acute lung injury. Circulation. 2000;102:2011-8.

38. Caser EB, Zandonade E, Pereira E, Gama AM, Barbas CS. Impact of distinct definitions of acute lung injury on its incidence and outcomes in Brazilian ICUs: prospective evaluation of 7,133 patients. Crit Care Med. 2014;42:574-82.

39. Hernu R, Wallet F, Thiolliere F, Martin O, Richard JC, Schmitt Z, et al. An attempt to validate the modification of the American-European consensus definition of acute lung injury/acute respiratory distress syndrome by the Berlin definition in a university hospital. Intensive Care Med. 2013;39:2161-70.

40. Young P, Hodgson C, Dulhunty J, Saxena M, Bailey M, Bellomo R, et al. End points for phase II trials in intensive care: recommendations from the Australian and New Zealand Clinical Trials Group consensus panel meeting. Crit Care Resusc. 2012;14:211-5.

41. Gajic O, Afessa B, Thompson BT, Frutos-Vivar F, Malinchoc M, Rubenfeld GD, et al. Prediction of death and prolonged mechanical ventilation in acute lung injury. Crit Care. 2007;11:R53.

42. Jegal Y, Lee SI, Lee KH, Oh YM, Shim TS, Lim CM, et al. The clinical efficacy of GOCA scoring system in patients with acute respiratory distress syndrome. J Korean Med Sci. 2008:23:383-9.

\section{Submit your next manuscript to BioMed Central and we will help you at every step:}

- We accept pre-submission inquiries

- Our selector tool helps you to find the most relevant journal

- We provide round the clock customer support

- Convenient online submission

- Thorough peer review

- Inclusion in PubMed and all major indexing services

- Maximum visibility for your research

Submit your manuscript at www.biomedcentral.com/submit
C Biomed Central 